Research Article

\title{
Influence of Crack on Concrete Damage in Salt-Freezing Environment
}

\author{
Guangyan Liu $\mathbb{D}^{1,2}$ Song Mu $\mathbb{D}^{1,2}$ Jingshun Cai, ${ }^{1,2}$ Deqing Xie, ${ }^{1,2}$ Ying Zhou, ${ }^{1,2}$ \\ and Xiaocheng Zhou ${ }^{1,2}$ \\ ${ }^{1}$ State Key Laboratory of High Performance Civil Engineering Material, Jiangsu Research Institute of Building Science, \\ Nanjing 210008, China \\ ${ }^{2}$ Jiangsu Sobute New Materials Co. Ltd., Nanjing 211103, China
}

Correspondence should be addressed to Song Mu; musong@cnjsjk.cn

Received 18 January 2021; Revised 22 April 2021; Accepted 7 June 2021; Published 16 June 2021

Academic Editor: Peng Zhang

Copyright ( 92021 Guangyan Liu et al. This is an open access article distributed under the Creative Commons Attribution License, which permits unrestricted use, distribution, and reproduction in any medium, provided the original work is properly cited.

The damage development trend of concrete with cracks in salt-freezing environment is systematically studied. The cracks are also tested in intact concrete for comparison, and crack characterization is introduced. The mass loss, the relative dynamic elastic modulus, and the change of crack width are analyzed. Results show that the crack width increases as the salt-freezing cycle progresses. Following the development trend of the cracks, concrete cracks can be divided into three categories: 0-40, 40-100, and $100-150 \mu \mathrm{m}$. The mass loss increases significantly, and the change of relative dynamic elastic modulus decreases in concrete with an initial crack compared with the intact concrete. When the crack width is $80 \mu \mathrm{m}$, a maximum mass loss rate of $0.19 \%$ and a minimum relative dynamic elastic modulus of $75.81 \%$ can be obtained. These test results prove that crack and freeze-thaw coupling can influence each other and accelerate the failure of concrete. Overall, this study can serve as a basis for the durability design and life improvement of concrete structures.

\section{Introduction}

With the construction of cross-sea bridges, concrete has been increasingly used in marine environments. Thus, the improvement of the durability of concrete material is a significant scientific issue for civil structure design [1]. In some cold areas, such as in northern China, the temperature is usually less than $0^{\circ}$, leading to the rapid degradation of the concrete. Frost attack on concrete is distress resulting from the phase transformation associated with the freezing of internal moisture. This phenomenon directly leads to the reduction of the cover and rusting of steel, affecting the service life of the concrete. In environments characterized by the presence of chloride ions, such as coastal environments and areas where deicing salts are used, the combination of freeze-thaw cycles and deicer salt application can seriously damage concrete $[2,3]$. The damage mechanism of saltfreezing is different from freezing and thawing damage. Deicing salt, employed to reduce the freezing point of water, alters the degree of saturation $[4,5]$ and reacts with the hydrated ordinary Portland cement (OPC), creating expansive reaction products that lead to cracking and distress [6-11]. The deterioration due to the erosive effect of deicing salt can develop rather rapidly than the destructive effect of normal freezing and thawing cycle on concrete. Consequently, the performance degradation of concrete is more serious under salt-freezing circumstances. The extensive use of deicing salts can result in the deterioration of concrete structures, such as pop-outs, exfoliations, and cracks, significantly affecting the service life of structures [12-15].

For concrete, cracks can form in various ways, including applied external force, temperature changes leading to volumetric mismatch, and internal chemical reactions usually caused by the ingress of aggressive chemicals [16-19]. Once cracks take form, they can provide a way for the chloride transport to the concrete [20-22]. Ingress of steel corrosive agents, such as water and air, will also accelerate, leading to higher chances of initiating corrosion 
$[23,24]$. Thus, many scholars investigated the effect of cracks on chloride ion transport. Jang et al. [25] studied the influence of cracks on chloride ion diffusion behavior in concrete. They found that the diffusion coefficient of chloride ion would not increase with the increase of the crack width until the so-called critical crack width is reached. When the crack width is larger than the critical value, the diffusion coefficient increases with the increase of the width, and the critical crack width obtained by the test varies from $55 \mu \mathrm{m}$ to $80 \mu \mathrm{m}$. Wang et al. [26] showed that when the crack width is between 100 and $400 \mu \mathrm{m}$, the diffusion coefficient of chloride ions in the crack increases rapidly with the increase of the crack width. Otherwise, the crack width has no obvious effects on chloride diffusion. Djerbi et al. [27] compared the influence of cracks on ordinary concrete and high-performance concrete by simulating chloride ion penetration in concrete. They proved that the diffusion coefficient of chloride ions in the crack increases with the increase of the crack width. When the crack width is greater than $80 \mu \mathrm{m}$, the diffusion coefficient of chloride ion in the crack is equal to the diffusion coefficient of chloride ion in water, which is independent of the concrete mix ratio.

The above studies were only a few of the increasing investigations on the salt frost damage on concrete. However, concrete with cracks has not yet been considered, and the factors leading to its rapid degradation in a marine environment remain unclear. Therefore, the frost damage resistance of concrete under cracking conditions requires further examination, which is helpful for the material's durability design and life prediction. The present study aims to determine how the development process of salt frost will damage concrete with crack and how the cracks influence salt frost damage. Specifically, the salt-freeze cycle is applied to the concrete specimens with initial cracks. After analyzing the mass loss of concrete, relative dynamic elastic modulus, and the change of crack width, the development trend of concrete damage under the coupled action of crack and the salt-freezing cycle is obtained.

\section{Preparation of Test Specimens and Applied Test Methods}

2.1. Materials. Type II52.5 OPC provided by JiangnanXiaoyetian Cement Co., Ltd., was used in the experiment. Fly ash (FA) and ground slag (SL) were also used to replace part of the cement as supplementary cementitious materials. FA and SL had replacement rates of $15 \%$ and $35 \%$, respectively. The chemical compositions were determined using X-ray fluorescence (XRF; Thermo Fisher Scientific ARL QUANTX), as shown in Table 1.

Fine aggregate was natural sand with a fineness modulus of 2.6 and an apparent density of $2640 \mathrm{~kg} / \mathrm{m}^{3}$. The basalt with particle size ranging from $5 \mathrm{~mm}$ to $15 \mathrm{~mm}$ and an apparent density of $2800 \mathrm{~kg} / \mathrm{m}^{3}$ was used as coarse aggregate. A $20 \%$ solid superplasticizer was applied to adjust the workability of fresh concrete. The air-entraining agent was also used to regulate $5 \%-6 \%$ of the air content. The above materials were provided by Jiangsu Sobute New Materials Co. Ltd.

Poremaster GT-60 produced by Quantachrome Instruments was used to test concrete porosity. Quanta 250 scanning electron microscopy (SEM) manufactured by FEI Company was employed to conduct microscopic analysis of the samples obtained after the salt-freezing cycle.

2.2. Sample Preparation. The $\mathrm{w} / \mathrm{b}$ used for concrete was 0.35 . The concrete mix proportion is shown in Table 2.

The concrete was mixed as follows. The cementitious materials and aggregate were added and mixed for $1 \mathrm{~min}$. Then, the superplasticizer and air-entraining agent were placed and stirred continuously for 2 mins. After stirring, the concrete samples with dimensions of $100 \times 100 \times 100 \mathrm{~mm}$ and $\varphi$ of $100 \times 200$ were cast. The cube samples were used to test the compressive strength, and the cylindrical samples were examined. The samples were removed from their mold on the next day. They were cured for another 28 days in $20 \pm 2^{\circ} \mathrm{C}$, under 95\% RH following the GB/T50081-2019. Subsequently, the compressive strength of the sample was determined using the pressure testing machine. The compressive strength of concrete was $56.9 \mathrm{MPa}$. The cylindrical samples were finally tested.

2.3. Preparation and Characterization of Cracks. Various methods can be used to prepare concrete cracks, such as the Brazilian splitting test, wedge splitting test, and three-point bending mode. Here, the method proposed by Toshiki on the basis of the Brazilian splitting test was employed. The Brazilian splitting test is simple and convenient, and thus, it is accepted by the majority $[25,28,29]$. However, due to the heterogeneity of concrete, controlling the formation and development of cracks in the loading process would be difficult, and the specimen might easily develop a fracture. In the present experiment, the method would use the PVC pipes to prevent specimen fracture.

After curing for 28 days, the samples with dry surfaces were put in PVC pipes whose one end was closed, as presented in Figures 1(a) and 1(b). Then, a low viscosity epoxy resin was used to fill the gap between PVC pipes and samples. A sample slice with a height of $50 \mathrm{~mm}$ was obtained for crack preparation. The details of the production process are presented in Figure 1. On the basis of the Brazilian splitting test, a linear variable differential transformer (LVDT) was used to monitor the crack width during the whole process, as shown in Figure 1(e). When the width reached the design value, the sample was removed, and the fracture parameters were characterized after $15 \mathrm{~min}$ [30] as the crack width would shrink after unloading.

After completing the crack preparation, the exact crack width was tested as follows: first, a glass slide with a size of $24.5 \times 76 \mathrm{~mm}$ was chosen as a reference. Then, a photograph of the crack was taken with the reference, as shown in Figure 2(a). Next, the reference and the cracking area were selected and binarized. Finally, the number of pixels of the selected area was determined. In the same photograph, the ratio of the cracking area was equal to the ratio of pixels. The pixel of the crack and reference and the area of the reference were obtained. Accordingly, the area of the reference was calculated. For simplicity, the length of the crack was assumed to be the diameter of the specimen, which was 
TABLE 1: Chemical compositions of the binder (\%).

\begin{tabular}{lccccccccc}
\hline Type & $\mathrm{SiO}_{2}$ & $\mathrm{CaO}_{2}$ & $\mathrm{Al}_{2} \mathrm{O}_{3}$ & $\mathrm{Fe}_{2} \mathrm{O}_{3}$ & $\mathrm{MgO}$ & $\mathrm{K}_{2} \mathrm{O}$ & $\mathrm{Na}_{2} \mathrm{O}$ & $\mathrm{SO}_{3}$ & $\mathrm{Others}$ \\
\hline OPC & 19.86 & 67.24 & 4.79 & 2.94 & 1.26 & 0.67 & 0.12 & 2.81 & 0.31 \\
FA & 40.00 & 12.50 & 33.10 & 5.61 & 0.65 & 0.96 & 0.38 & 3.30 & 3.5 \\
SL & 32.20 & 41.10 & 14.4 & 1.04 & 6.38 & 0.53 & 0.35 & 2.23 & 1.77 \\
\hline
\end{tabular}

TABLe 2: Concrete mix proportion $\left(\mathrm{kg} / \mathrm{m}^{3}\right)$.

\begin{tabular}{lccccccc}
\hline Cement & SL & FA & Water & Sand & Aggregate & Superplasticizer & Air-entraining agent \\
\hline 240.00 & 168.00 & 72.00 & 168.00 & 735.84 & 1625.86 & 2.68 & 0.04 \\
\hline
\end{tabular}

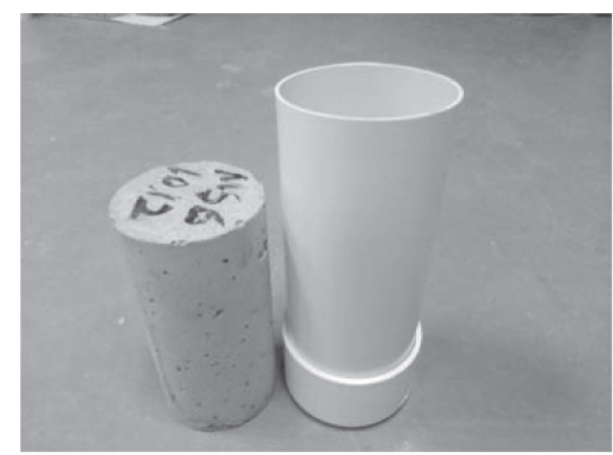

(a)

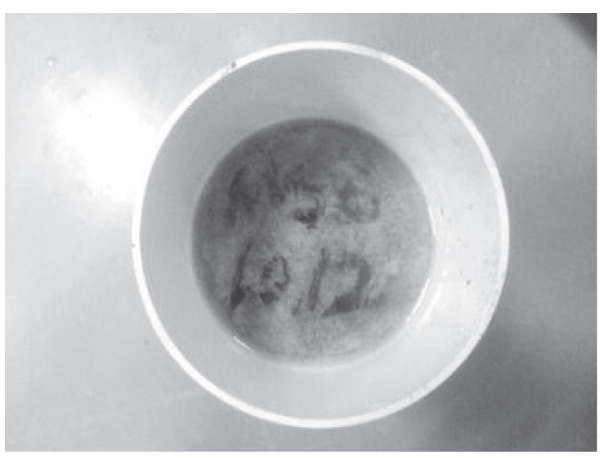

(c)

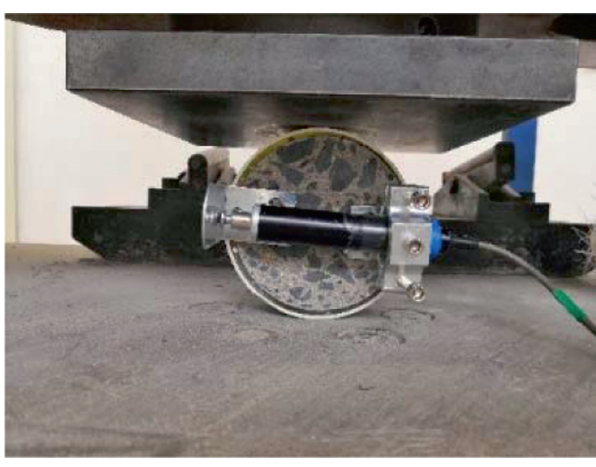

(e)

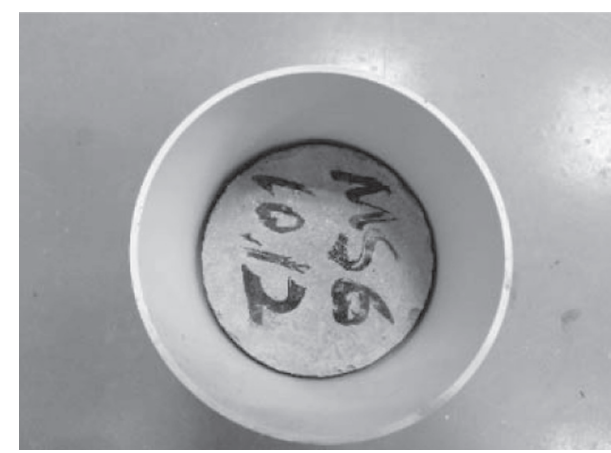

(b)

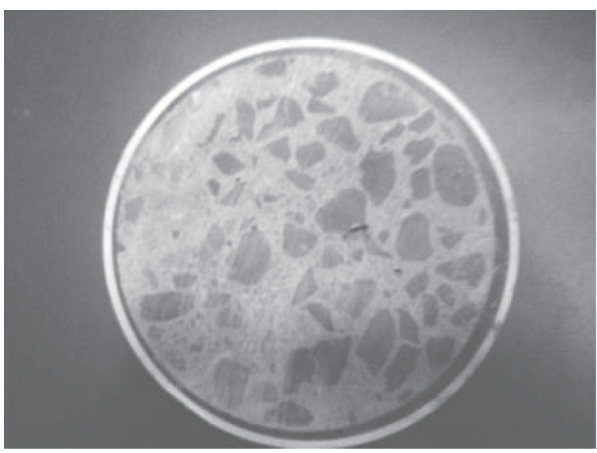

(d)

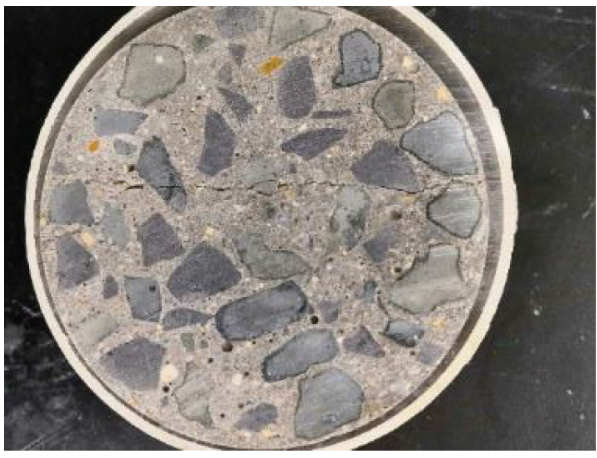

(f)

Figure 1: Preparation process of cracks in concrete specimens.

$100 \mathrm{~mm}$. Thus, the width of the crack was equal to the area divided by the length.

On the basis of the above method, the final crack width was divided into seven groups: $20,40,60,80,100,130$, and
$150 \mu \mathrm{m}$. In the subsequent test, the width of each group was considered to be the actual crack width. The width error of each group was $5 \mu \mathrm{m}$. The detailed grouping is shown in Table 3. 


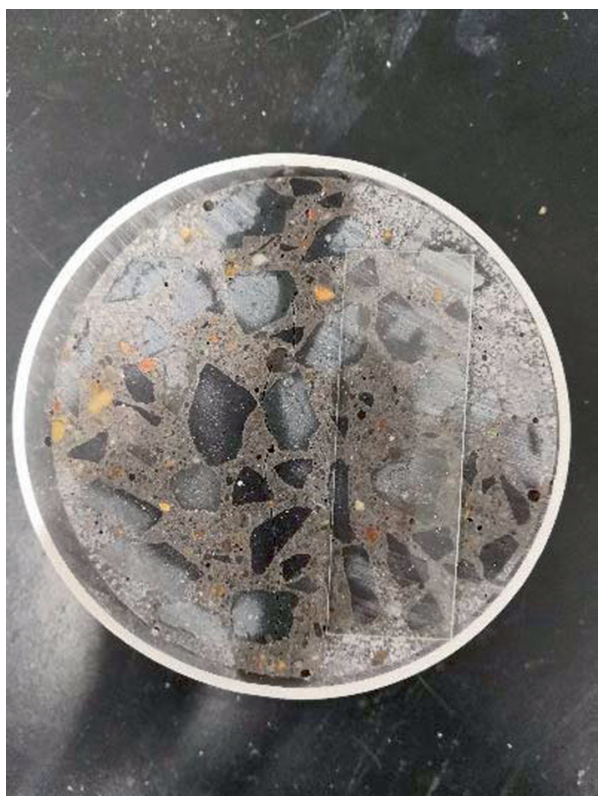

(a)

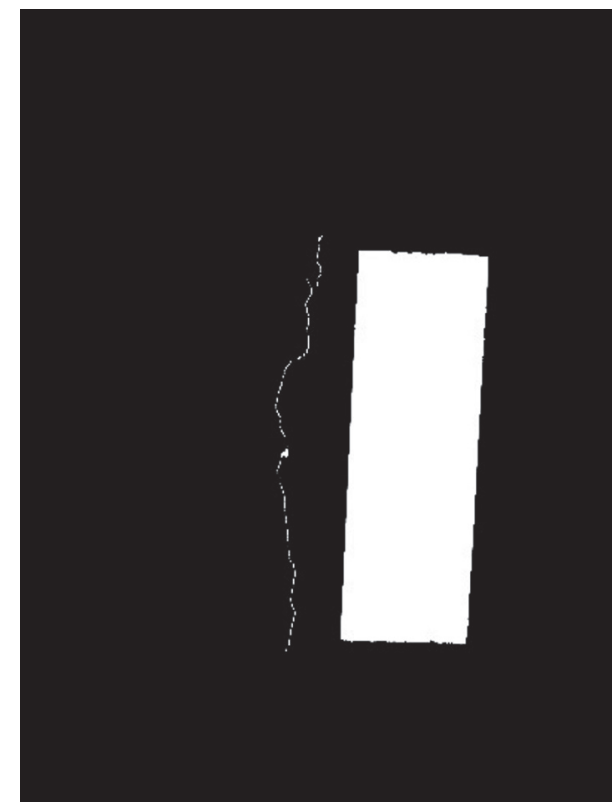

(b)

FIgURE 2: Fracture characterization process.

TABLE 3: Grouping of cracks of different widths.

\begin{tabular}{lccccccc}
\hline Group width $(\mu \mathrm{m})$ & 20 & 40 & 60 & 80 & 100 & 130 & 150 \\
\hline Actual crack width $(\mu \mathrm{m})$ & $15-25$ & $35-45$ & $55-65$ & $75-85$ & $95-105$ & $125-135$ & $145-155$ \\
\hline
\end{tabular}

2.4. Salt-Freezing Testing Procedure. These tests were run following the GB/T50082-2009 Chinese standard. In this case, the sodium chloride $(\mathrm{NaCl})$ solution had a similar mass concentration of $3 \%$ as the freeze-thaw solution. The test surfaces of the samples were placed in $3 \% \mathrm{NaCl}$ solution for seven days for solution uptake by capillary suction. The temperature in the box varied between $+20^{\circ} \mathrm{C}$ and $-20^{\circ} \mathrm{C}$. A cycle of freezing and thawing lasted for $12 \mathrm{~h}$, and the test only started when the temperature in the box was $20^{\circ} \mathrm{C}$. In the first cycle, the samples were cooled at $10^{\circ} \mathrm{C}$ per hour for $4 \mathrm{~h}$ until the temperature was $-20^{\circ} \mathrm{C}$. This setup was maintained for $3 \mathrm{~h}$. Then, they were heated up at a rate of $10^{\circ} \mathrm{C}$ per hour. Finally, the temperature was kept at $20^{\circ} \mathrm{C}$ for $1 \mathrm{~h}$ to complete the cycle. The temperature change during a cycle is shown in Figure 3. The specimens were characterized by the crack width and number of freeze-thaw cycles. For example, D28C8 indicates that the specimens had a crack width of $80 \mu \mathrm{m}$ and were exposed to freeze-thaw cycles 28 times.

Following the GB/T50082-2009 standard, the related parameters were tested every four cycles (two days). The damage of specimens was reflected by the relative dynamic elastic modulus and scaling mass. After four cycles, the flaking material was collected, dried, and weighed. The measurement of ultrasonic transit time was a standardized test method used to determine the variation in the relative dynamic elastic modulus with time. Ultrasonic transducers were positioned to arrange the axis of the ultrasonic transit path perpendicular to the specimen surface and parallel to

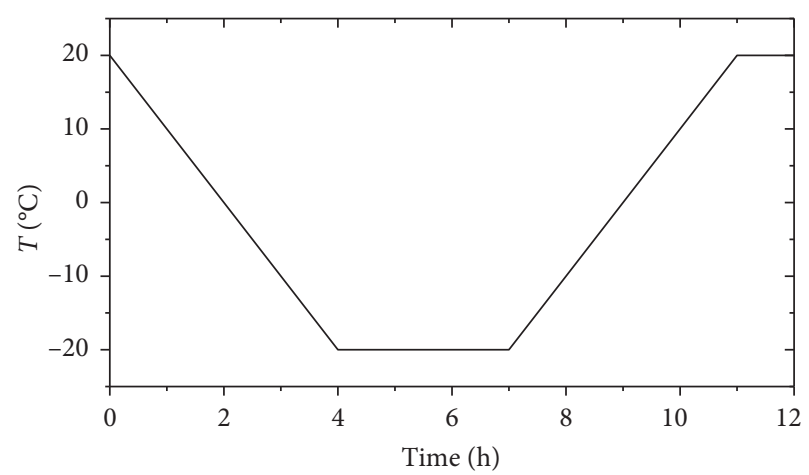

FIGURE 3: Salt-freezing cycle temperature system.

the crack depth direction. The transit time in the coupling medium was calculated from the velocity of the ultrasonic signal and the transit length in the coupling medium. In this experiment, ZBL-U510 nonmetallic ultrasonic detector was used to test the ultrasonic transmission time.

The relative dynamic elastic modulus was determined using the following equations:

$$
\begin{aligned}
\tau_{n} & =\frac{t_{0}-t_{c}}{t_{n}-t_{c}} \times 100, \\
E_{d} & =\tau_{n}^{2} \times 100,
\end{aligned}
$$

where $E_{d}$ is the relative dynamic elastic modulus of the specimen $(\%), \tau_{n}$ is the ultrasonic wave relative propagation 
time of the specimen (\%), $t_{0}$ is the total propagation time of ultrasonic wave in the specimen and coupling agent $(\mu \mathrm{s}), t_{n}$ is the total propagation time of ultrasonic wave in the specimen and coupling agent after $n$ cycles $(\mu \mathrm{s})$, and $t_{c}$ is the propagation time of ultrasonic waves in the coupling agent.

At the same time, a camera was used to take photos of the specimen. The photographs were processed to observe the changes in the crack width and sampling for porosity and microscopic testing.

\section{Results and Discussion}

3.1. Crack Width. The effect of salt-freezing cycles on the crack width of concrete is presented in Figure 4. The initial crack width was roughly $60 \mu \mathrm{m}$, as shown in Figure 4(a). After the 8th, 16th, and 28th cycles, the crack widths indicated in Figure 4 were increased to 164.51, 193.58, and $268.01 \mu \mathrm{m}$. In other words, the crack width increased with the extension of the cycle period.

The damage development of the crack width with the increase in salt-freezing cycle periods is shown in Figure 5. The initial crack width of less than $40 \mu \mathrm{m}$ gradually increased at the early and late stages, with the increase of the cycle period. In the initial stage, due to the small crack widths, considering, self-healing and other factors, the increase of crack width was relatively slow. However, with the continuous increase of the crack width, the self-healing ability was weakened. The bigger the crack width, the easier it for the solution to be absorbed by the concrete, leading to internally and externally salt-induced freezing damage and a significant increase in the crack width.

In the later period of salt-freezing cycle, concrete cracks tended to shrink. The identification and detection of cracks were mainly based on the software. With the development of salt-freezing cycle, on the one hand, flaking led to particles blocking cracks. On the other hand, the damage range of the specimen generally extended from the fracture area to both sides, making it difficult to identify fractures. Consequently, the crack width obtained by the test was reduced. For specimens with crack width less than $40 \mu \mathrm{m}$, the initial crack width was small, and the damage caused by salt-freezing was not serious, so this phenomenon did not occur at all.

Following the development trend of cracks, concrete cracks could be concluded as three categories. For the crack width of less than $40 \mu \mathrm{m}$, the salt-freezing cycle almost did not affect the crack development at the early stage. However, it caused a rapid growth for the crack width at the later stage. For the crack widths ranging from $40 \mu \mathrm{m}$ to $100 \mu \mathrm{m}$, the saltfreezing cycle resulted in rapid growth at the first 20 cycles. The crack width remained stable or gradually decreased after 20 cycles. For the crack widths greater than $100 \mu \mathrm{m}$, the development trend of the cracks was similar, and the width was almost identical. To sum up, no obvious effect was observed on the crack development when the crack width was more than $100 \mu \mathrm{m}$. Moreover, for the cracks at different widths to reach the maximum growth rate of the crack widths, the number of salt-freezing cycles required is gradually reduced. For the crack widths of 40, 80, and $130 \mu \mathrm{m}$, the number of cycles required to achieve the maximum growth rate of the crack width was 28,20 , and 16 times, respectively.

3.2. Mass Loss Rate. The mass loss rate of the specimen after 28 salt-freezing cycles is shown in Figure 6. At the stage where the crack width was less than $20 \mu \mathrm{m}$, no obvious effect was observed on its mass loss rate. When the crack width was ranging from $20 \mu \mathrm{m}$ to $80 \mu \mathrm{m}$, the mass loss rate sharply increased. The maximum mass loss rate was $0.19 \%$, which was obtained when the crack width was $80 \mu \mathrm{m}$. Afterward, the curve slowly decreased. The mass loss of surface undamaged concrete (crack width of $0 \mu \mathrm{m}$ ) was minimal, indicating that the surface cracks could significantly affect the salt-freezing resistance and reduce the durability of the specimen. Moreover, the increase of the crack width and contact parts between the specimen surface and salt solution increased the scaling mass.

The mass loss of the specimens with different crack widths along with the salt-freezing cycle is shown in Figure 7. With the increase of the crack width, the mass loss gradually increased. At the early stage of the salt-freezing cycle, the mass scaling of concrete specimens was not obvious, and the mass scaling rate was low. With the increase of the salt-freezing cycle period, the quality loss of the specimen increased gradually. The mass loss also increased when the freeze-thaw cycle was more than eight times. With the continuous salt-freezing cycle, the peeling quality gradually increased, and the mass loss rate increased. The reason might be the gradual accumulation of the damage of the specimen. Given the existence of cracks, the salt solution could enter into the concrete through the cracks and cause damage. At the early stage of the salt-freezing cycle, no significant differences were observed in the scaling quality between specimens with different fracture widths, indicating that the effect of fracture width on the scaling quality was not obvious at this time. As the number of salt-freezing cycles went on, the effect of the fracture width on the scaling quality gradually increased.

3.3. Relative Dynamic Modulus of Elasticity. The propagation of ultrasonic waves in concrete was affected by the matrix compactness and microcracks. The damage of concrete was determined by testing the change of ultrasonic wave transmission time in concrete. Ultrasonic testing of concrete was carried out in a direction perpendicular to the crack, as shown in Figure 8.

The change of the relative dynamic elastic modulus of the specimen with the salt-freezing cycle under different fracture conditions is displayed in Figure 9.

When the crack width was less than $20 \mu \mathrm{m}$, the relative dynamic elastic modulus of concrete decreased slightly, and the damage occurred only in the later stages of the saltfreezing cycle. In Figures 9(c) and 9(d), the relative dynamic elastic modulus of concrete dropped sharply, whose crack width was 60 and $80 \mu \mathrm{m}$ by $75.92 \%$ and $75.81 \%$. However, when the crack width was 100 and $130 \mu \mathrm{m}$, the relative dynamic modulus was only slightly reduced. By contrast, when the crack width was $80 \mu \mathrm{m}$, the relative dynamic 


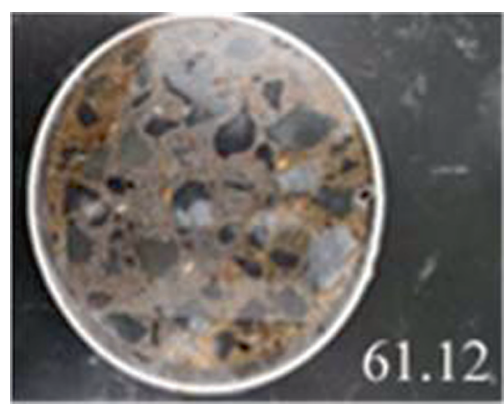

(a)

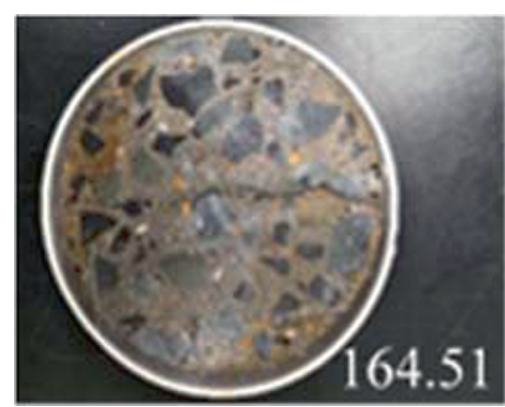

(b)

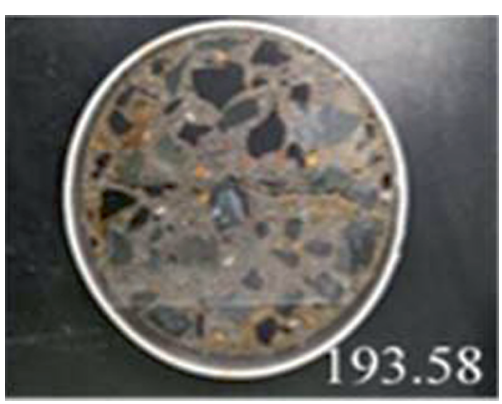

(c)

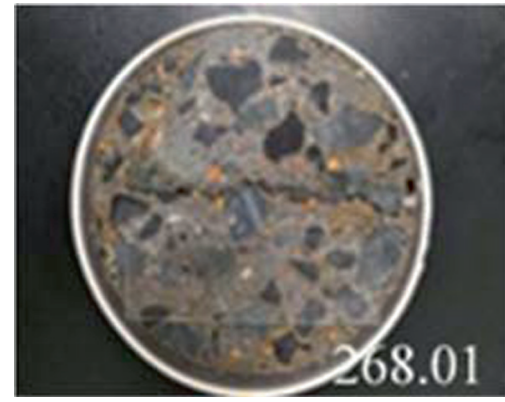

(d)

FIGURE 4: The development of concrete damage under different salt-freezing cycle periods: (a) 0, (b) 8th, (c) 16th, and (d) 28th cycles.

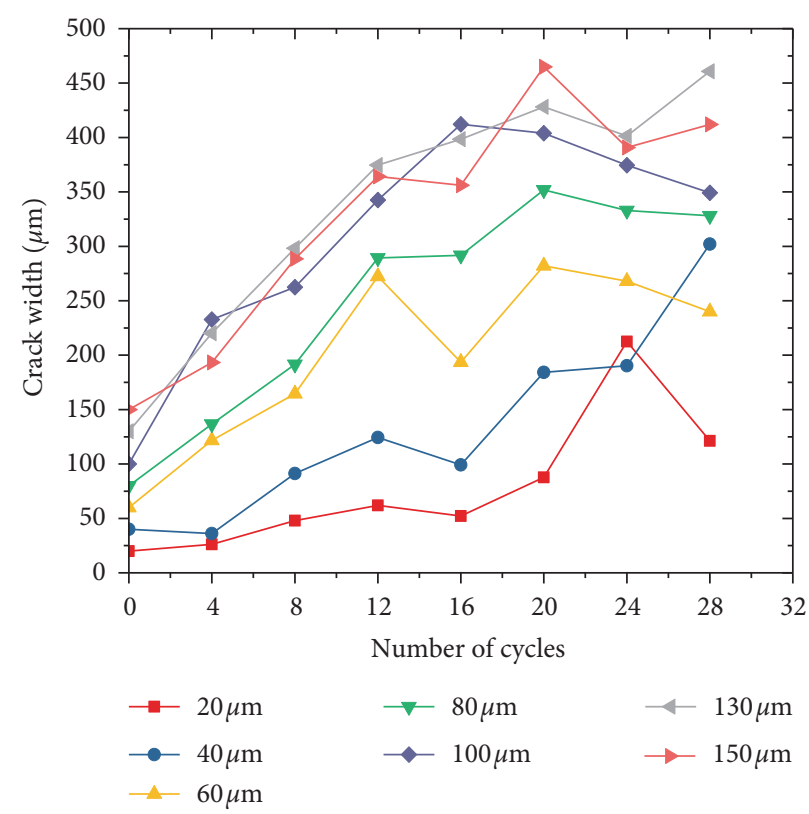

FIGURE 5: The fracture development of the specimens under different salt-freezing cycles.

modulus did not continue to reduce as the crack width increases. Given the gradual damage accumulation, the relative dynamic modulus of all the specimens did not excessively change. The maximum change was only $92.96 \%$ when the width was $60 \mu \mathrm{m}$ during the first eight salt-freezing cycles. In the early stage of the salt-freezing cycle, the microcracks were produced in the sample, and the relative dynamic elastic modulus did not change significantly. As the cycle progresses, the damage of the sample and the peeling were intensified. Macroperformances decreased in relative dynamic modulus of elasticity.

The relative dynamic elastic modulus of the sample after completion of all salt-freezing cycles under different initial crack widths is shown in Figure 10. Without any produced cracks, the relative dynamic modulus of the specimen was 93\% after 28 salt-freezing cycles. However, the relative 


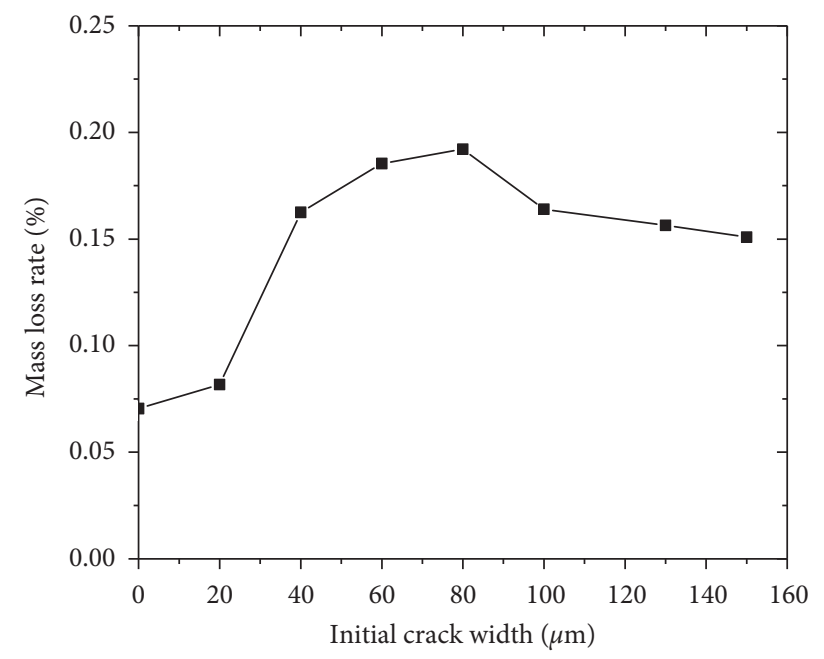

FIGURE 6: The mass loss rate of the specimens after 28 salt-freezing cycles.

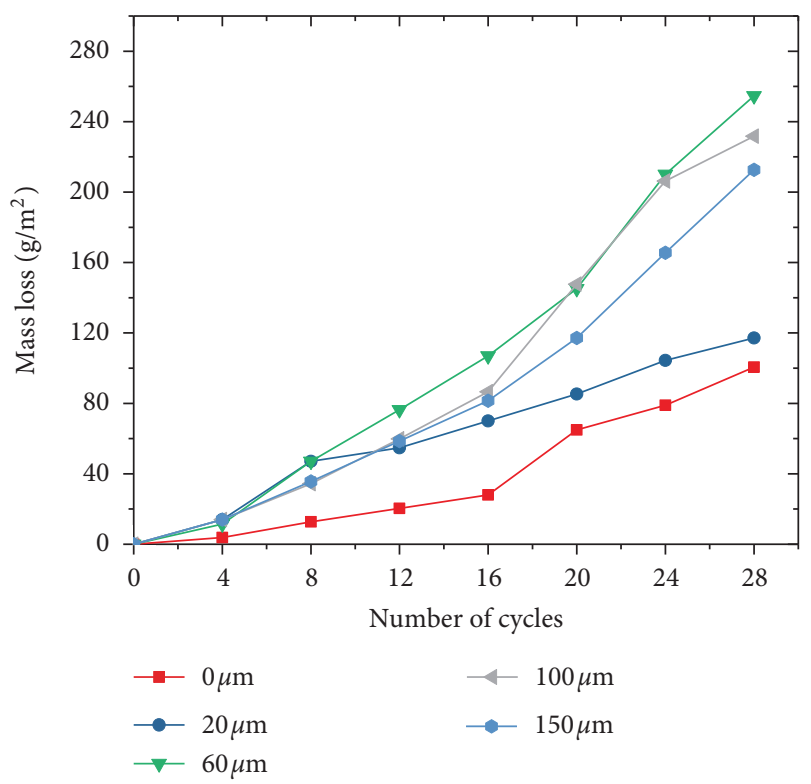

FigURE 7: Mass loss of specimens with different salt-freezing cycles.

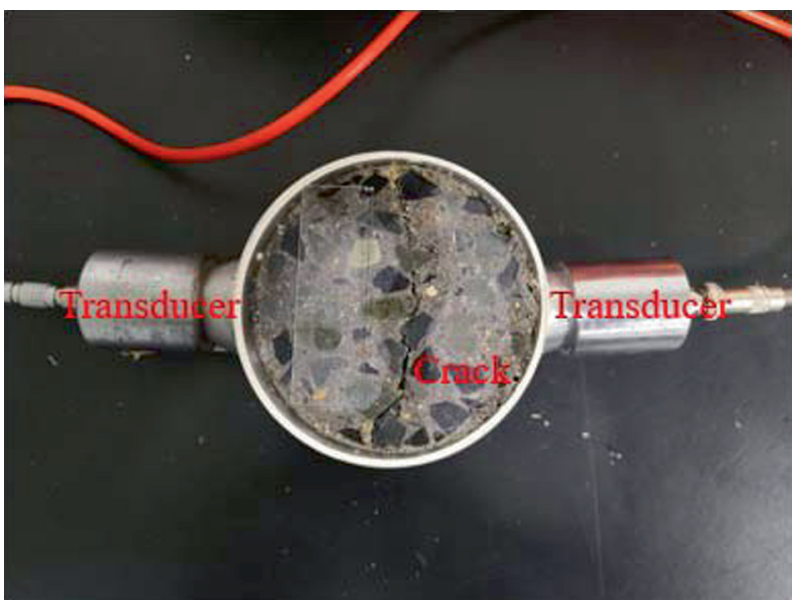

Figure 8: Diagram of the ultrasonic test. 

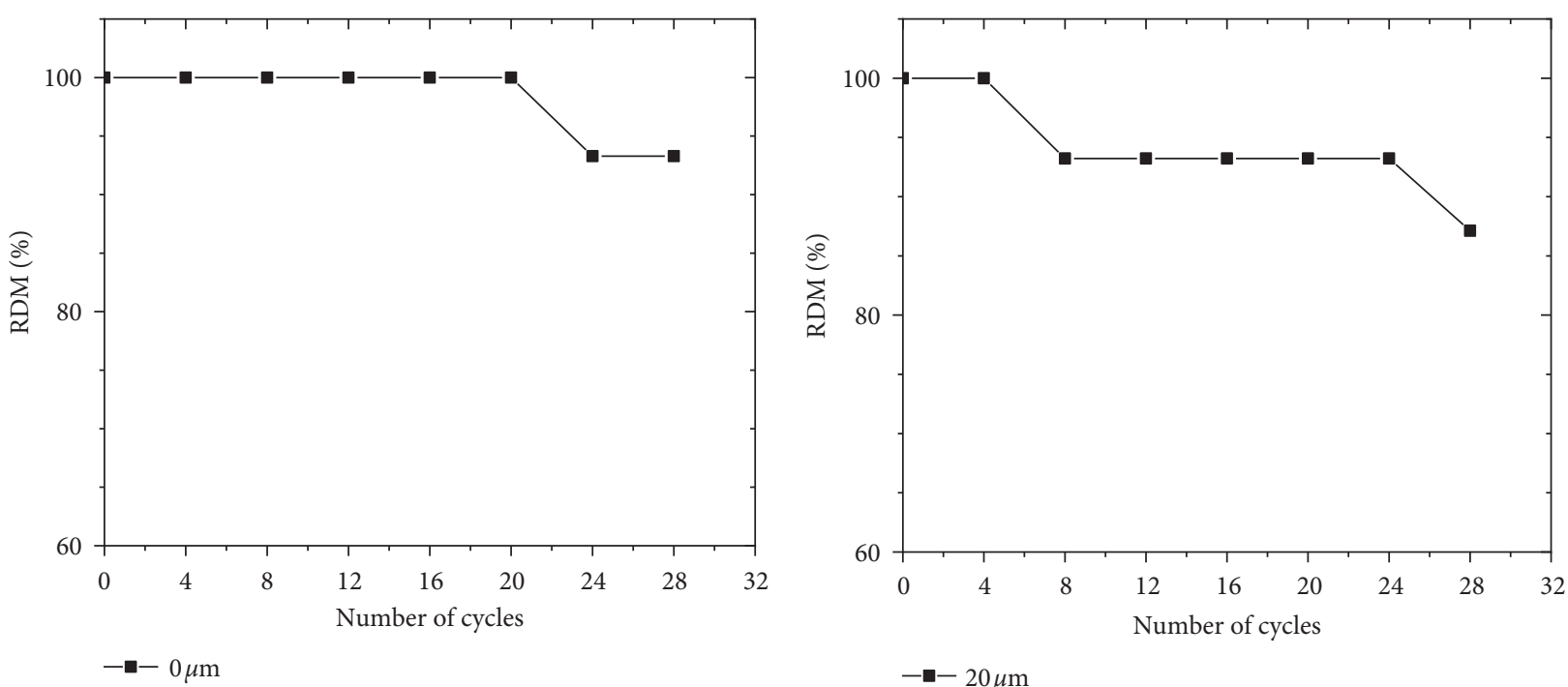

(a)
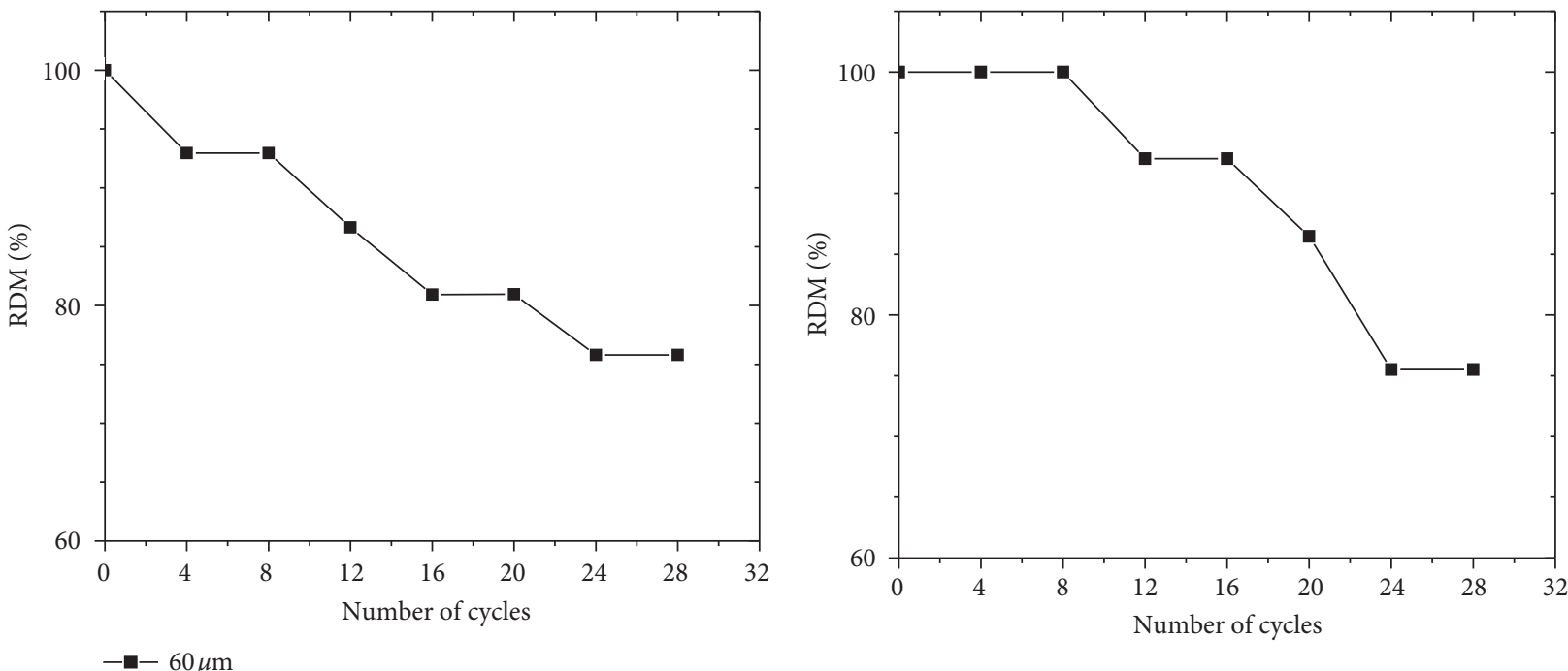

(c)

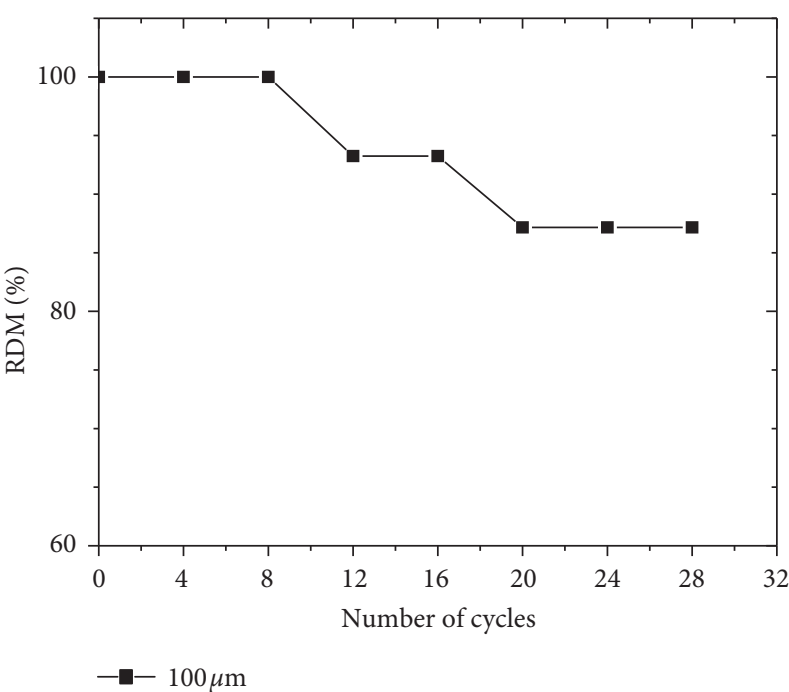

(d)

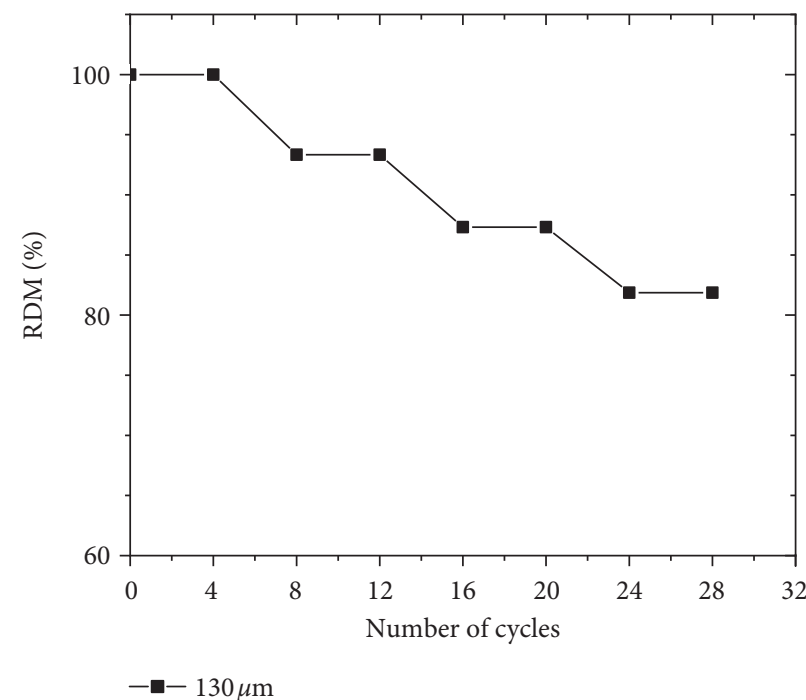

(e)

(f)

Figure 9: Changes in the relative dynamic elastic modulus of the specimens with the salt-freezing cycle: (a) 0, (b) 20, (c) 60, (d) 80, (e) 100, and (f) $130 \mu \mathrm{m}$. 


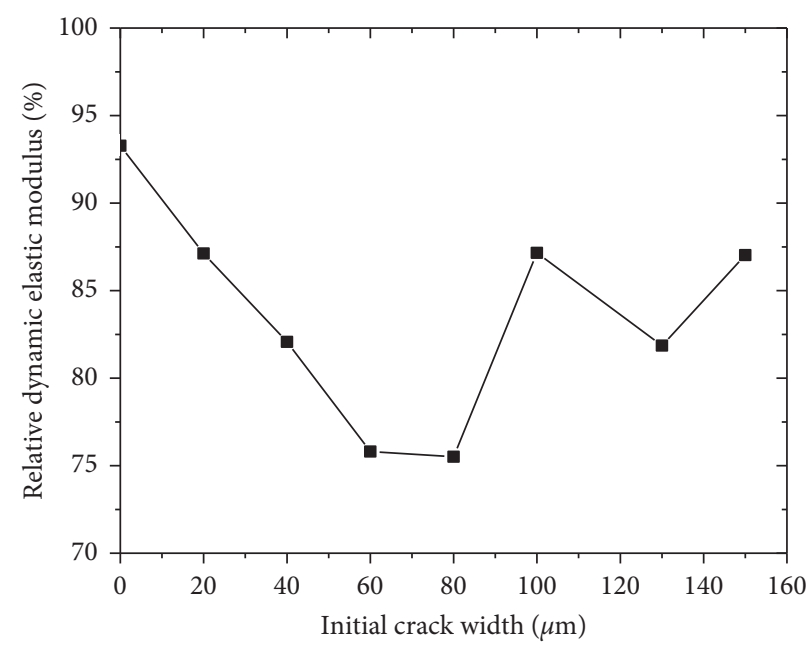

FIgURE 10: Changes in the relative dynamic elastic modulus of concrete after 28 salt-freezing cycles.

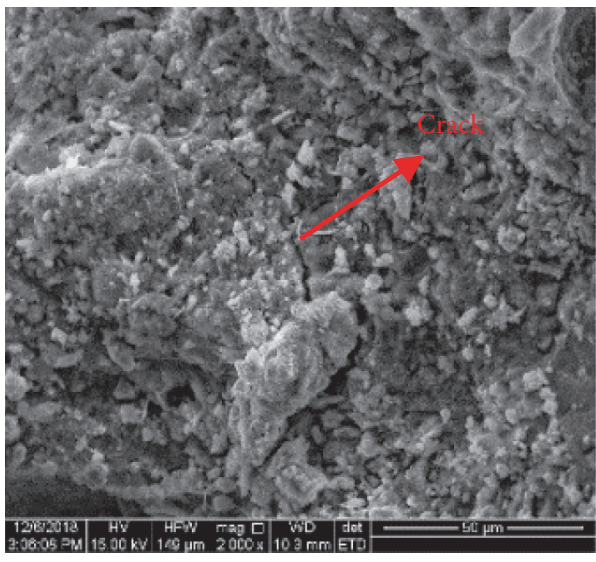

(a)

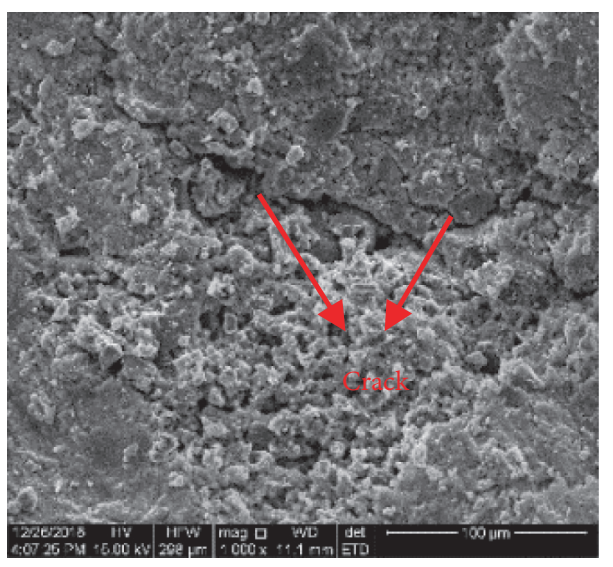

(c)

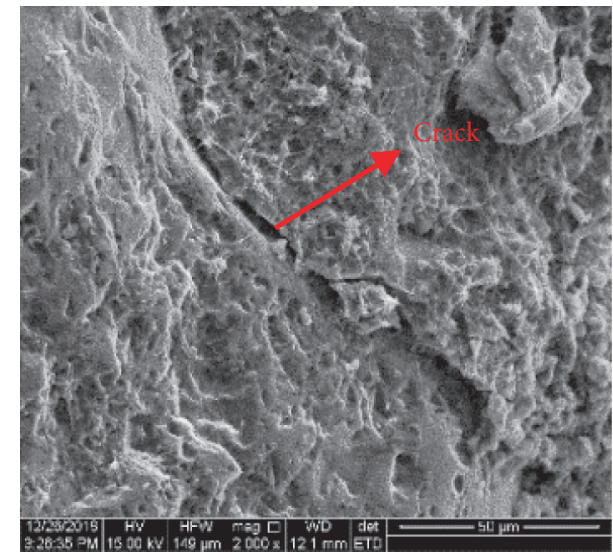

(b)

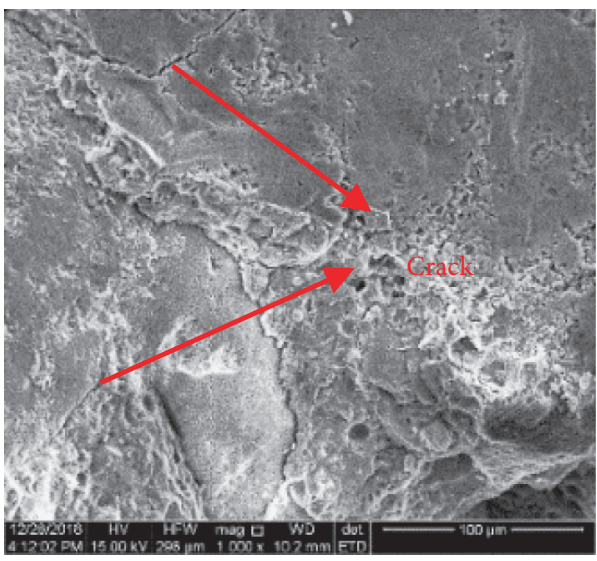

(d)

Figure 11: Continued. 


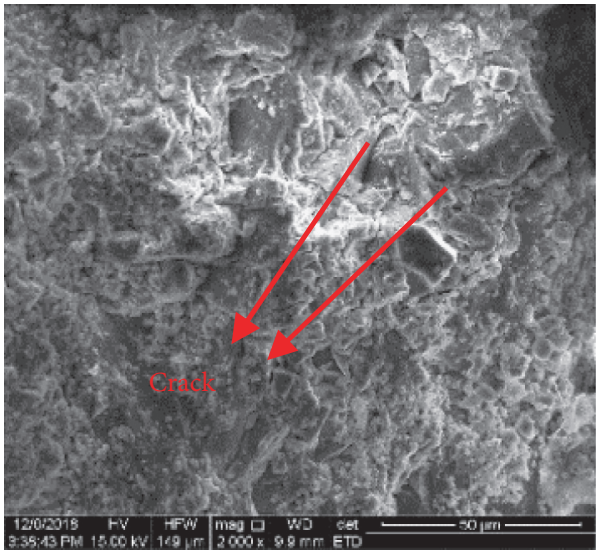

(e)

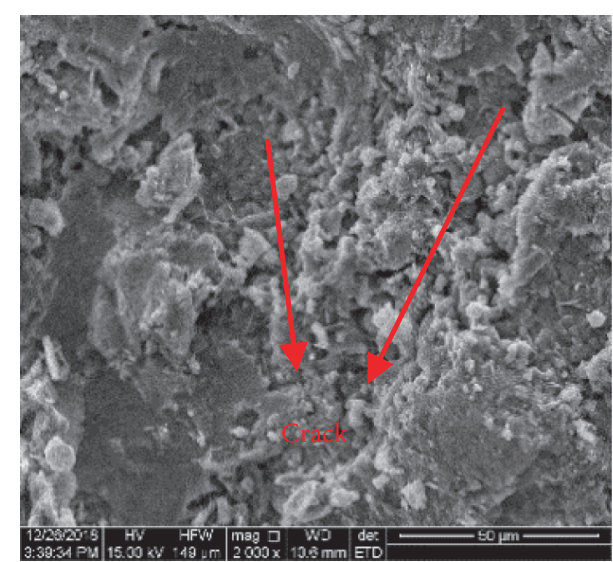

(f)

FIGURE 11: SEM photographs of the concrete under different salt-freezing cycles. (a) D0C0, (b) D28C2, (c) D28C6, (d) D28C8, (e) D28C10, and (f) D8C13.

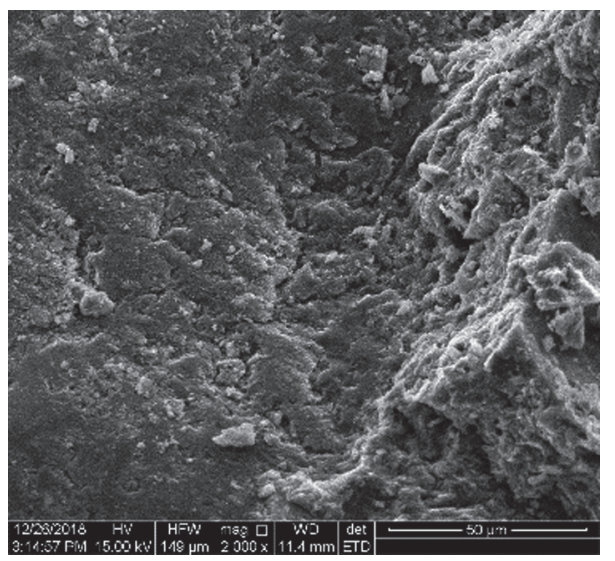

(a)

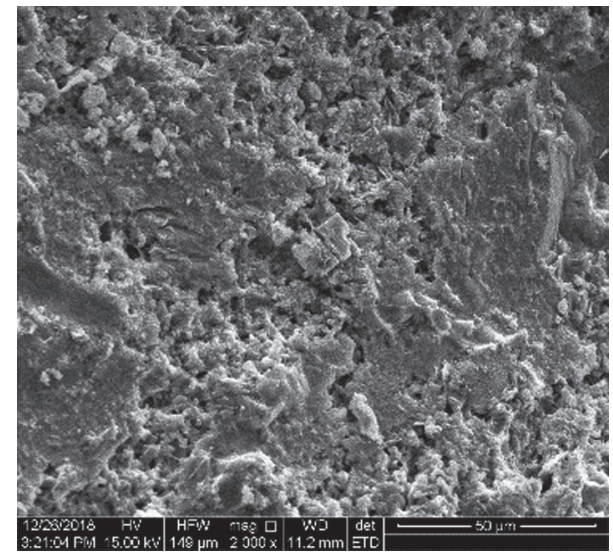

(b)

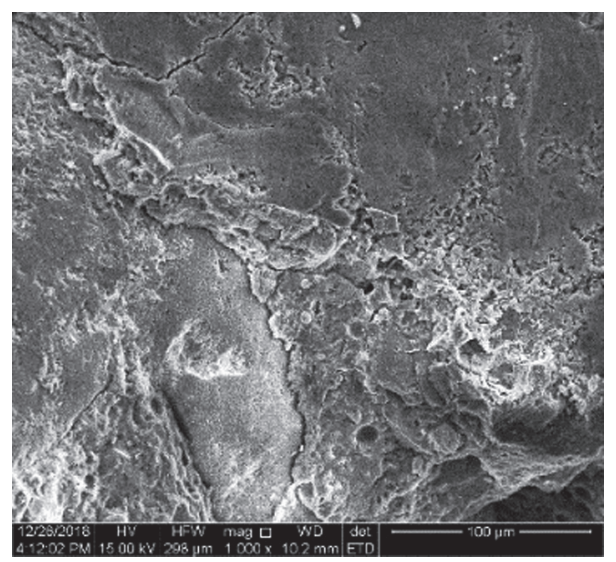

(c)

FIgURE 12: SEM photographs of the concrete under different salt-freezing cycles. (a) D8C8, (b) D16C8, and (c) D28C8.

dynamic modulus was $87.12 \%, 82.07 \%, 75.92 \%, 75.81 \%$, $87.16 \%, 81.86 \%$, and $87.03 \%$ for the sample with the crack widths of $20,40,60,80,100,130$, and $150 \mu \mathrm{m}$, respectively. The existence of cracks led to simultaneous surface and internal damage. Therefore, after completing all the salt- freezing cycles, the relative dynamic elastic modulus was markedly reduced compared with the intact concrete sample. Considering that the relative dynamic elastic modulus mainly represented the internal damage degree of the specimen, the cracks in the specimen led to the increase 


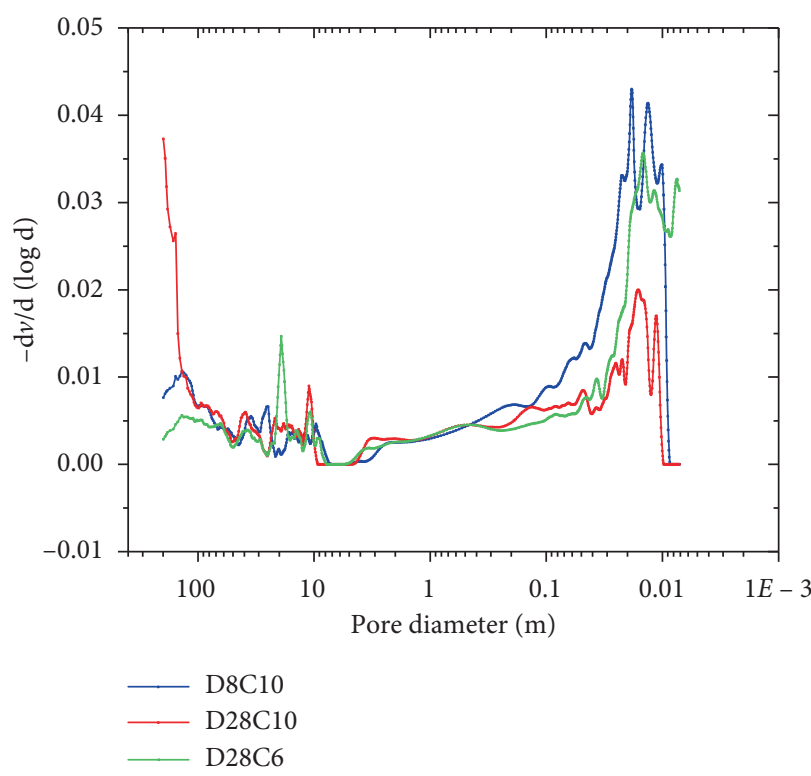

(a)

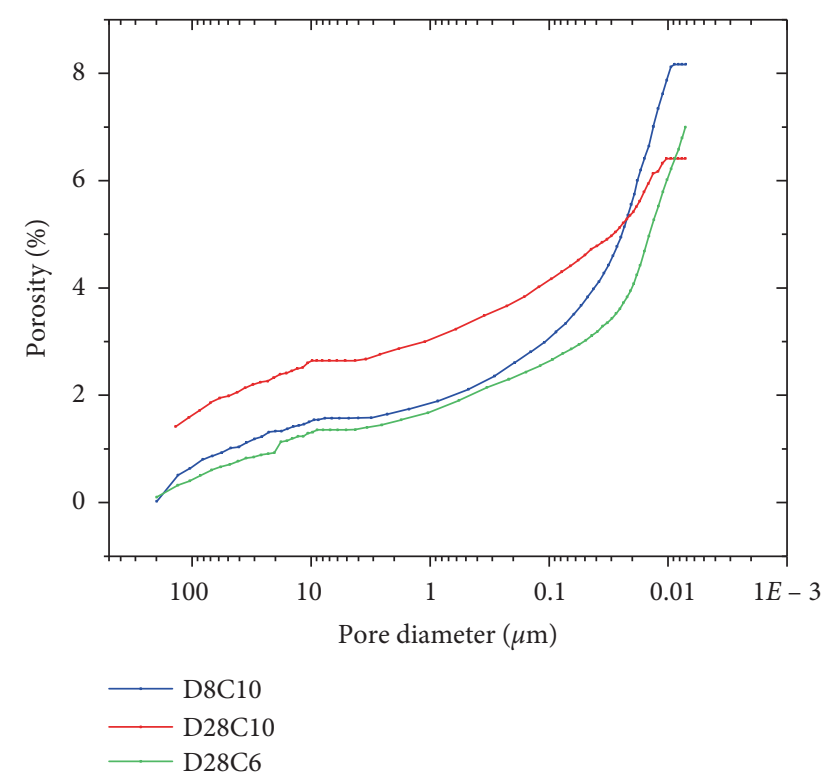

(b)

FIGURE 13: Pore size distribution of specimens with different crack widths and salt-freezing cycles: (a) most probable pore radius and (b) porosity.

of the internal damage degree. When the crack width was less than $80 \mu \mathrm{m}$, the larger the crack width, the more obvious the decrease of the relative dynamic modulus of the specimen. The specimen would be more easily damaged in the salt-freezing cycle. However, at the stage where the crack width was greater than $80 \mu \mathrm{m}$, the relative dynamic elastic modulus exhibited the opposite trend, except when the crack width was $100 \mu \mathrm{m}$.

For the mass loss, obvious damage was produced in concrete specimens with an initial crack after eight saltfreezing cycles. When the crack width was $80 \mu \mathrm{m}$, the concrete was most likely to be damaged, and the destruction was the most serious in a salt-freezing environment.

3.4. Microstructure and Porosity. The SEM images of the samples with the initial crack after 28 salt-freezing cycles are shown in Figure 11. Although cracks were observed in the concrete that did not undergo the salt-freezing cycle, their number was small, and the CSH gel was relatively complete and dense. After completing the salt-freezing cycle, the integrity of the specimen was damaged, and the peeling of small particles led to internal potholes and increased mass loss. When the crack width was $20 \mu \mathrm{m}$, the CSH gel was pitted, and the integrity was damaged. As the crack width increases, the damage to the specimen increases. For example, in the stage where the crack width was ranging from $60 \mu \mathrm{m}$ to $80 \mu \mathrm{m}$, the microcracks inside the specimen significantly increased, and the crack expansion caused the specimen to peel. The damage of the specimen was the most serious when the crack width was $130 \mu \mathrm{m}$, and the CSH gel produced microholes. The damage caused by freezing and thawing resulted in many microcracks in the specimen. These damages led to the scaling of the specimen. As a new transmission channel, microcracks accelerated the entry of chloride ions and water into the specimen. Thus, they could aggravate the damage degree of the next freeze-thaw cycle. The larger the crack width, the more serious was the microstructure damage and the more evident the damaging effect would be. Given the damage, more solutions entered the pores, further leading to the degradation of concrete. This coupling effect was also one of the reasons why the damage of cracked concrete was worse than that of intact concrete.

The SEM images of the specimens with the same crack width at the 8th, 16th, and 28th salt-freezing cycles are shown in Figure 12. The damage of concrete increased gradually with the salt-freezing cycle. Similarly, the degree of surface scaling aggravation and the number of microcracks increased. The increase in the salt-freezing cycle periods gradually accumulated damage to the specimens aggravated.

The changes in the void fraction during the salt-freezing cycle are shown in Figure 13. The samples with a crack width of $100 \mu \mathrm{m}$ had the most probable pore radius increase and porosity diminution after completing all the salt-freezing cycles compared with only eight cycle periods. Salt-freezing caused the generation of tiny cracks. Many small damages, whether newly generated or originally in the specimen, increased gradually. Consequently, the most probable pore radius also increased. The voids grew and communicated with one another to form large damage, causing a decrease in porosity. For the specimen with a crack width of $60 \mu \mathrm{m}$, the most probable pore radius increased significantly after 28 cycles, but the change in the void fraction was not obvious compared with the specimens with a crack width of $100 \mu \mathrm{m}$. Yet, the porosity and most probable pore radius of $\mathrm{D} 28 \mathrm{C} 10$ slightly changed in contrast to sample D8C10. This result proved that the influence of the crack width on concrete was 
greater than that of the freeze-thaw cycle, which was more likely to cause pore size increase and concrete damage.

\section{Conclusion}

In this study, the damage development trend of concrete with initial cracks in a salt-freezing environment was systematically examined. The development of cracks in concrete, the mass loss, the change of relative dynamic elastic modulus, and the change of microstructure and void ratio were tested. On the basis of the test results, the following conclusions can be drawn:

(1) The crack width increases with salt-freezing. The larger the initial crack width, the larger the crack width will be. For the specimens with a crack width of less than $40 \mu \mathrm{m}$, the crack width develops slowly in the initial stage but rapidly at the later stage. The crack widths ranging from 40 to $100 \mu \mathrm{m}$ have exhibited rapid growth. However, for the specimens with a crack width greater than $100 \mu \mathrm{m}$, under the same salt-freezing cycle, the crack width is almost the same, indicating that the influence of the initial crack width can be ignored.

(2) Under cracking conditions, the salt-free cycle exacerbates the damage of concrete. The mass loss and the relative dynamic elastic modulus have obvious changes compared with the intact concrete. In addition, the influence of the crack width on concrete damage is greater, and the acceleration effect on the concrete failure is more obvious than the salt cycles.

(3) The SEM results show that the damage of concrete increases gradually with a continuous salt-freezing cycle. The peeling of small particles leads to internal potholes and mass loss. The larger the crack width is, the more serious the microstructure damage and the more evident the damaging effect. Salt-freezing also leads to the most probable pore radius increase and porosity diminution.

(4) The concrete with an initial crack has developed internal and surface damage compared with the intact concrete. Therefore, the surface and internal cracks and the pores of the specimen tend to fall off and increase, respectively. In other words, corrosive substances, such as chloride ions, can diffuse into the concrete through the surface and pass through the cracks. Consequently, substances can easily enter the concrete, causing durability problems, such as steel corrosion, and affecting the service life.

\section{Data Availability}

The data and charts used to support the findings of this study are available within in the article.

\section{Conflicts of Interest}

The authors declare that they have no conflicts of interest.

\section{Acknowledgments}

The authors are grateful for the financial support provided by the National Natural Science Foundation of China (U1706222) and the China Railway First Survey and Design Institute Group Co., Ltd. (20-16-2).

\section{References}

[1] S. Jacobsen, H. C. Gran, E. J. Sellevold, and J. A. Bakke, "High strength concrete-freeze/thaw testing and cracking," Cement and Concrete Research, vol. 25, no. 8, pp. 1775-1780, 1995.

[2] A. B. Harnik, U. Meier, and A. Rosw, "Combined influence of freezing and delcing salt on concrete - physical aspects," Durability of Building Materials and Components ASTMSTP, vol. 69, pp. 474-484, 1980.

[3] J. Deja, "Freezing and de-icing salt resistance of blast furnace slag concretes," Cement and Concrete Composites, vol. 25, no. 3, pp. 357-361, 2003.

[4] R. P. Spragg, J. Castro, W. Li, M. Pour-Ghaz, P. T. Huang, and J. Weiss, "Wetting and drying of concrete using aqueous solutions containing deicing salts," Cement and Concrete Composites, vol. 33, no. 5, pp. 535-542, 2011.

[5] C. Villani, R. Spragg, M. Pour-Ghaz, and W. Jason Weiss, "The influence of pore solutions properties on drying in cementitious materials," Journal of the American Ceramic Society, vol. 97, no. 2, pp. 386-393, 2014.

[6] Y. Farnam, D. Bentz, A. Hampton, and W. J. Weiss, "Acoustic emission and low-temperature calorimetry study of freeze and thaw behavior in cementitious materials exposed to sodium chloride salt," Transportation Research Record: Journal of the Transportation Research Board, vol. 2441, no. 1, pp. 81-90, 2014.

[7] Y. Farnam, H. Todak, R. Spragg, and J. Weiss, "Electrical response of mortar with different degrees of saturation and deicing salt solutions during freezing and thawing," Cement and Concrete Composites, vol. 59, pp. 49-59, 2015.

[8] Y. Farnam, D. Bentz, A. Sakulich, D. Flynn, and J. Weiss, "Measuring freeze and thaw damage in mortars containing deicing salt using a low-temperature longitudinal guarded comparative calorimeter and acoustic emission," Advances in Civil Engineering Materials, vol. 3, pp. 316-337, 2014.

[9] Y. Qian, Y. Farnam, and J. Weiss, "Using acoustic emission to quantify freeze-thaw damage of mortar saturated with nacl solutions," in Proceedings of the International Conference on the Durability of Concrete Structures, pp. 32-37, West Lafayette, IN, USA, July 2014.

[10] Y. Farnam, S. Dick, A. Wiese, J. Davis, D. Bentz, and J. Weiss, "The influence of calcium chloride deicing salt on phase changes and damage development in cementitious materials," Cement and Concrete Composites, vol. 64, pp. 1-15, 2015.

[11] Y. Farnam, A. Wiese, D. Bentz, J. Davis, and J. Weiss, "Damage development in cementitious materials exposed to magnesium chloride deicing salt," Construction and Building Materials, vol. 93, pp. 384-392, 2015.

[12] X. Shi, L. Fay, M. M. Peterson, and Z. Yang, "Freeze-thaw damage and chemical change of a portland cement concrete in the presence of diluted deicers," Materials and Structures, vol. 43, no. 7, pp. 933-946, 2010.

[13] J. J. Valenza and G. W. Scherer, "A review of salt scaling: I. Phenomenology," Cement and Concrete Research, vol. 37, no. 7, pp. 1007-1021, 2007. 
[14] K. Wang, D. E. Nelsen, and W. A. Nixon, "Damaging effects of deicing chemicals on concrete materials," Cement and Concrete Composites, vol. 28, no. 2, pp. 173-188, 2006.

[15] W. Sun, R. Mu, X. Luo, and C. Miao, "Effect of chloride salt, freeze-thaw cycling and externally applied load on the performance of the concrete," Cement and Concrete Research, vol. 32, no. 32, pp. 1859-1864, 2002.

[16] Z. Li and S. P. Shah, "Localization of microcracking in concrete under uniaxial tension," ACI Materials Journal, vol. 91, pp. 372-381, 1994.

[17] H. Zhao, K. Jiang, B. Hong et al., "Experimental and numerical analysis on coupled hygro-thermo-chemo-mechanical effect in early-age concrete," Journal of Materials in Civil Engineering, vol. 33, no. 5, Article ID 04021064, 2021.

[18] H. Zhao, X. Wu, Y. Huang, P. Zhang, Q. Tian, and J. Liu, "Investigation of moisture transport in cement-based materials using low-field nuclear magnetic resonance imaging," Magazine of Concrete Research, vol. 73, no. 5, pp. 252-270, 2021.

[19] H. Zhao, K. Jiang, R. Yang, Y. Tang, and J. Liu, "Experimental and theoretical analysis on coupled effect of hydration, temperature and humidity in early-age cement-based materials," International Journal of Heat and Mass Transfer, vol. 146, Article ID 118784, 2020.

[20] C. M. Aldea, S. P. Shah, and A. Karr, "Effect of cracking on water and chloride permeability of concrete," Journal of Materials in Civil Engineering, vol. 11, no. 3, pp. 181-187, 1999.

[21] M. Hoseini, V. Bindiganavile, and N. Banthia, "The effect of mechanical stress on permeability of concrete: a review," Cement and Concrete Composites, vol. 31, no. 4, pp. 213-220, 2009.

[22] M. B. Otieno, M. G. Alexander, and H.-D. Beushausen, "Corrosion in cracked and uncracked concrete - influence of crack width, concrete quality and crack reopening," Magazine of Concrete Research, vol. 62, no. 6, pp. 393-404, 2010.

[23] B. Pease, M. Geiker, H. Stang, and J. Weiss, "The design of an instrumented rebar for assessment of corrosion in cracked reinforced concrete," Materials and Structures, vol. 44, no. 7, pp. 1259-1271, 2011.

[24] F. Hiemer, S. Keßler, and C. Gehlen, "Development of chloride induced reinforcement corrosion in cracked concrete after application of a surface protection system," in Proceedings of the Concrete Solutions 6 th International Conference on Concrete Repair, Thessaloniki, Greece, June 2016.

[25] S. Y. Jang, B. S. Kim, and B. H. Oh, "Effect of crack width on chloride diffusion coefficients of concrete by steady-state migration tests," Cement and Concrete Research, vol. 41, no. 1, pp. 9-19, 2011.

[26] H. L. Wang, J. G. Dai, X. Y. Sun, and X. L. Zhang, "Characteristics of concrete cracks and their influence on chloride penetration," Construction and Building Materials, vol. 107, pp. 216-225, 2016.

[27] A. Djerbi, S. Bonnet, A. Khelidj, and V. Baroghel-Bouny, "Influence of traversing crack on chloride diffusion into concrete," Cement and Concrete Research, vol. 38, no. 6, pp. 877-883, 2008.

[28] S. S. Park, S. J. Kwon, and S. H. Jung, "Analysis technique for chloride penetration in cracked concrete using equivalent diffusion and permeation," Construction and Building $\mathrm{Ma}$ terials, vol. 29, pp. 183-192, 2012.

[29] O. G. Rodriguez and R. D. Hooton, "Influence of cracks on chloride ingress into concrete," ACI Materials Journal, vol. 100, no. 2, pp. 120-126, 2003.
[30] V. Picandet, A. Khelidj, and H. Bellegou, "Crack effects on gas and water permeability of concretes," Cement and Concrete Research, vol. 39, no. 6, pp. 537-547, 2009. 